Diánoia, vol. 15, no. 15, 1969

\title{
LA FILOSOFIA Y LAS ACTITUDES MORALES
}

\begin{abstract}
"What is conventionally called 'philosophy' consists of two very different elements. On the one hand, there are questions which are scientific or logical; these are amenable to methods as to which there is general agreement. On the other hand, there are questions of passionate interest to large numbers of people, as to which there is no solid evidence either way. Among the latter are practical questions as to which it is impossible to remain aloof." Bertrand Russell: History of Western Philosophy, 1946, cap. XXVII.
\end{abstract}

1. Podemos usar el término filosofía en varios sentidos, pero voy a considerar solamente dos fundamentales. En su acepción más amplia, la palabra filosofía alude a ciertas representaciones o doctrinas que pretenden expresar la estructura del mundo por medio de una conexión más o menos coherente de conceptos o simplemente de imágenes. En estos intentos, el filósofo trata de comprender a un tiempo el destino de sí mismo y el sentido del mundo, por eso presenta entrelazadas sus ideas sobre la estructura última de la realidad con principios de valor y con ideales morales que dan razón de la conducta de un individuo o de una comunidad entera. De esta manera, puede decirse que todo hombre realiza su vida a partir de una imagen del mundo - por muy pobre o rudimentaria que ésta sea. Igualmente puede decirse que los principios y los ideales que este hombre adopta, son inseparables de sus actitudes morales e integran un todo orgánico con sus creencias, a veces también con sus argumentos y con la información de que dispone acerca de la realidad. La filosofía, en este sentido amplio de la palabra, forma parte de la personalidad como una atmósfera indispensable para entender la vida psicológica y moral de los individuos; es también una manifestación cultural ligada estrechamente a la circunstancia histórica y, por tanto, necesaria para entender el desarrollo de determinadas comunidades humanas, inclusive de naciones enteras. Precisamente en los resultados de tal actividad pensaba Dilthey cuando proponía una teoría de las concepciones del mundo para exponer el curso histórico de la religiosidad, de la poesía y de la metafísica, con el objeto de esclarecer la relación del espíritu humano con el enigma del mundo, en oposición a todo relativismo.

En este sentido lato, el término no excluye ninguna de las escuelas o corrientes filosóficas del pasado, ni siquiera las concepciones míticas -en cierta medida prefilosóficas- del mundo. Así considerada, la filosofía no constituye un género único, ni puede definirse por sus métodos de trabajo o por ocuparse de un campo de problemas bien determinado. En lo que 
hace a los métodos, acepta la mayor variedad de procedimientos que cabe imaginar, inclusive la apelación a puntos de vista sobrenaturales o la pretensión de alcanzar verdades más allá de toda crítica racional. En lo que hace a sus problemas, la filosofía, que parece abarcarlo todo, apenas puede dejar fuera de sus dominios ciertas cuestiones meramente dogmáticas de la teología y, por supuesto, las investigaciones empíricas o formales de las ciencias especializadas bien delimitadas. Una historia de la filosofia, entendida de esta manera, permitiría colocar al lado de los grandes clásicos de la disciplina, sendos capítulos dedicados, por ejemplo, a Dante o a Byron, a Leonardo o a Nietzsche, a Copérnico o a Einstein. Y tal historia de la filosofía puede ser escrita, ateniéndose no tanto a las doctrinas como a las personalidades filosóficas, es decir, a los hombres que aparecen solidariamente ligados por una búsqueda común -éste es el caso de la historia publicada por $\mathrm{N}$. Abbagnano. O también puede escribirse poniendo el acento en las circunstancias sociales y políticas en que surgieron las doctrinas - como la historia de la filosofía occidental publicada por B. Russell. En todo caso, es en este contexto en donde adquiere pleno valor el apotegma que Fichte escribió en su Primera introducción a la teoría de la ciencia: "Qué clase de filosofía se elige, depende de qué clase de hombre se es; pues un sistema filosófico no es como un ajuar muerto, que se puede dejar o tomar, según nos plazca, sino que está animado por el alma del hombre que lo tiene."

Pero también usamos el término filosofía en un sentido más estricto, para referirnos a una determinada empresa intelectual, analítica y teórica, que dominada por una energía propiamente científica se enfrenta a problemas de diversa índole - por ejemplo, lógicos, semánticos, epistemológicos-, haciendo uso de ciertos métodos sobre los cuales, como ha dicho Russell en el texto del epígrafe, hay un acuerdo general. Otros idiomas cuentan con términos específicos para mantener la distinción: así el alemán que utiliza la palabra Weltanschauıng para designar lo que nosotros tratamos como filosofía en su sentido amplio. Weltanschauung ha venido a sustituir la tradicional Weltweisheit, limitada al conocimiento de las cosas del mundo por oposición al saber de las cosas divinas. En español sucede esto último cuando hablamos del pensamiento de los moralistas o utilizamos la palabra sabiduria, puesto que aceptamos la limitación del término a un saber acerca de las tareas humanas. Lo que no acontece con la sagesse francesa que no separa, como nosotros, sabiduria y sapiencia.

En este ensayo no se trata de señalar los rasgos característicos de la filosofía en sentido estricto oponiéndolos a los de la filosofía considerada como sabiduría o concepción del mundo; tampoco se trata de discurrir sobre sus métodos y precisar la indole de sus problemas, menos todavía de caracterizar sus resultados teóricos y críticos. Lo que se pretende es solamente aclarar un cierto ángulo de aquella distinción y destacar una conexión fun- 
damental entre las dos actividades, que contribuya a hacer más visible lo mismo su relación en el plano teórico que su posible compatibilidad práctica. Sin que esto quiera decir que no puedan darse otras conexiones.

El asunto presenta muchas dificultades, aunque no todas surjan a la primera mirada, simplemente porque conduce a una enorme masa de cuestiones diferentes, más o menos conectadas entre sí, que tradicionalmente han sido conceptuadas con una terminología muy poco precisa; terminología que además registra algunas de las nociones de mayor significación dentro de la historia de las teorías morales. Sin mencionar aquellas que se refieren a aspiraciones, valoraciones o ideales; ni aquellas que aluden a ideas, prejuicios, convicciones o creencias; todavía quedan, por ejemplo: reacción, resorte, respuesta, instinto, orientación, inclinación, dirección adquirida, tendencia, actitud, aptitud, hábito, adaptación, posición, suposición, disposición, predisposición, anticipación, postura, pơrte, talante, sentimiento, emoción, afición, motivación, elección, decisión, determinación, punto de vista, compromiso, experiencia, carácter, comportamiento, personalidad y muchas otras que encaran a veces el mismo fenómeno $u$ otros fenómenos cercanos. Por estas razones, el propósito de este ensayo queda prudentemente reducido a un solo punto: la elucidación de un solo concepto, el concepto de actitud, y el intento de mostrar su relación con la sabiduría o concepción del mundo. La conclusión provisional consistirá en señalar la posibilidad de la función crítica de la filosofía en sentido estricto, frente a los productos culturales de la sabiduria y, de manera indirecta, frente a las actitudes morales a partir de las cuales aquéllos se originan. Pero este señalamiento, dadas las limitaciones de espacio, quedará reducido a la mera indicación de algunas vías que pueden ser exploradas en estudios posteriores.

2. Antes de decir algo sobre el concepto de actitud tal como es usado en el lenguaje científico, debemos recordar la forma en que se emplea en nuestras conversaciones cotidianas. Se dice, por ejemplo, que "alguien adopta" o "toma una actitud determinada a partir de un cierto momento"; o que "alguien mantiene una determinada actitud" o la "abandona". En estos casos, como en otros semejantes, entendemos claramente que no se quiere dar cuenta de un acontecimiento singular, sino que se nos indica que tenemos derecho a esperar un cierto comportamiento por parte de la persona a que se refieren aquellas expresiones; más precisamente, se nos dice que tal persona tiene, a partir de un determinado momento, una propensión $o$ inclinación a actuar de cierta manera, de acuerdo con las situaciones a que tenga que enfrentarse.

Acerquémonos un poco más al ejemplo. Cuando se dice: "Juan Pérez ha adoptado una actitud estoica", no se hace la narración de un episodio relativo a la conducta pasada de Juan o a su vida intima, sino que se hace una advertencia que nos autoriza a esperar cosas como éstas: lejos de toda 
reacción frívola, Juan se conducirá ante los problemas de la vida diaria como un hombre sinceramente preocupado por el ejercicio de la virtud; independientemente de las tareas profesionales de Juan, es probable que esta preocupación esté por encima de cualquiera otra de orden teórico y contribuya a una cierta autosuficiencia, tal vez consecuente con un sereno desprecio de los apetitos y de las pasiones, con un desapego de los bienes materiales, con una especial capacidad para la soledad, para aceptar los golpes del destino y enfrentar la muerte. Aún podríamos esperar más, en el caso de que Juan Pérez fuera hombre de aficiones intelectuales; el anuncio de su actitud nos autorizaría a suponerlo un racionalista y enemigo de todo escepticismo, no sólo en cuestiones de orden moral sino aun tratándose de la estructura del mundo, hasta el punto de creer que sus ideales personales de sabiduría y virtud forman parte de ese orden cósmico. $Y$ todavía podríamos añadir parecidas consideraciones, si ampliamos nuestro ejemplo al campo de la religión o de la política, pero tal cosa no es indispensable para tratar los puntos que interesan en este ensayo $y$, en cambio, tiene el riesgo de conducirnos a una serie de problemas adicionales.

Nuestro ejemplo de actitud moral es suficiente para mostrar que, en el lenguaje ordinario, el uso disposicional que hacemos de la palabra actitud nos autoriza a esperar de un sujeto ciertas actuaciones, es decir, cierta conducta coherente y, sobre todo, constante, aunque el concepto no excluya de manera absoluta la evolución progresiva y hasta la mutación brusca. Cuando alguien adopta una actitud, queda comprometido a ponerla en práctica en todas las circunstancias pertinentes, no en el sentido de repetir mecánicamente las posturas que la han actualizado en el pasado, sino en el de la congruencia frente a las situaciones nuevas. Hasta tal punto es claro este compromiso, que la congruencia o la constancia en el mantenimiento de una actitud se conectan ordinariamente con ciertos rasgos de carácter que se valoran muy alto desde el punto de vista de la moralidad y con otras nociones como autorrealización y autenticidad que constituyen también un elemento esencial de la vida moral. Para ser en verdad morales o inmorales nuestras acciones, deben ser consistentes en alguna medida, deben formar parte de un conjunto orgánico de acciones que, de alguna manera actualizan prácticamente una actitud. Y nuestros juicios morales se relacionan por partida doble con las actitudes, en tanto que no juzgan sobre una acción aislada y en tanto que responden en su orientación a las actitudes que persisten en nosotros mismos.

También decimos, en el lenguaje corriente, "adoptar un método" o "abandonarlo", cuando queremos indicar una serie de operaciones tácticas para alcanzar determinada meta; pero no podemos decir, por ejemplo, "adoptar un método ante la vida", y esto último no parece una mera diferencia en niveles de complejidad, si bien tal diferencia es notoria. Adoptar una 
actitud moral no es nada más acogerse a un código de normas para obtener ciertos resultados al enfrentar circunstancias determinadas, previstas por el código, porque esto difícilmente podría comprometernos con lo no previsto y, por otra parte, quedaría sujeto a la condición de ser eficaz en el logro de los resultados. En cambio, el adoptar una actitud queda libre de tales condiciones, lo cual no quiere decir que se trate de una disposición a reaccionar de tal manera general que no pueda precisar situaciones y delimitar los objetos a los cuales se va a enfrentar como tal actitud; más bien sucede lo contrario, la generalidad de la actitud - como podría mostrarse en el ejemplo dado-, abarca todos los aspectos posibles de la vida y la conducta humana en cualquier circunstancia, pero presenta estos aspectos bien jerarquizados y organiza las situaciones desde una perspectiva. Sobre este punto habrá ocasión de volver más adelante, pero por ahora debe quedar claro que mientras el abandono de un método es algo aconsejable en cuanto sobreviene el primer fracaso -en esto precisamente puede residir la congruencia de la tarea científica-, el abandono de una actitud es, en principio, independiente de sus resultados. La fidelidad a una actitud moral es loable no sólo en el éxito sino ante todo en el fracaso frente a las presiones y cambios de la situación, pero el empecinamiento en el empleo de tácticas ineficaces de investigación no es siquiera comprensible.

Podría pensarse que nuestro ejemplo de actitud es un tanto complejo y hasta sofisticado; pero la verdad es que en el lenguaje ordinario, como en el de las ciencias sociales, nunca hablamos de actitudes en abstracto sino precisamente de actitudes determinadas, que no suelen ser menos artificiosas que en el ejemplo dado. Además, el ejemplo nos permite llamar la atención sobre ciertos elementos característicos de toda actitud. Otro más simple nos conduciría de cualquier manera, en un declive inevitable, a las actitudes de más alto rango que pretenden legislar para todos los hombres o, al menos, justificar la conducta propia ante los puntos de vista y los intereses ajenos. Conviene precisar desde ahora que el término no incluye simplemente una serie de simpatías y diferencias, es decir, de preferencias y aversiones, aspiraciones $y$ deseos, amores y odios más o menos caprichosos. Se trata de algo mucho más complejo, a la vez más restringido y probablemente menos arbitrario: decimos que alguien ha adoptado una actitud cuando estamos seguros de a) su disposición para actuar de cierta manera; b) su disposición para hacer cierta clase de juicios; c) su disposición para experimentar los estados emocionales que normalmente acompañan aquellas acciones y estos juicios, y por último $d$ ) poder establecer cierta conexión entre tales acciones, juicios y estados emocionales con otros, producidos o experimentados por el mismo sujeto, que guardan con ello alguna semejanza.

3. Los hombres de ciencia y los filósofos han ido mucho más allá en el intento de precisar el concepto de actitud. Los fisiólogos, por ejemplo, 
han reclamado para sí el derecho a emplear el término en su sentido más. general, dentro del dominio de la motricidad, como una manera de mantener el cuerpo. Emplean actitud como sinónimo de posición al referirse a las piezas del esqueleto y definir su localización en el espacio; o también como sinónimo de postura al referirse a las distintas partes del cuerpo animadas por la musculatura, que presuponen una actividad que no está implicada en la posición del esqueleto. Pero también, aplican la voz actitud a la descripción de un conjunto de posturas, a una "postura constante" y además "total", esto último en el sentido de que abarca todo el cuerpo, no sólo una parte o un miembro.

Probablemente con excepción de los conductistas, que no buscan en la actitud un estado subjetivo inasible sino que se atienen al sentido más general del término como comportamiento complejo cuyo desarrollo se puede preveer a partir de ciertos signos objetivos, la mayoría de los psicólogos conservó por mucho tiempo la ambigüedad que afecta a la palabra desde sus origenes. $\mathrm{Al}$ parecer, la palabra actitud deriva de aptitud (en latín aptitudo), entendida como disposición natural para cumplir ciertas tareas; y fue introducida por la crítica de arte para describir, en las representaciones plásticas, "la posición del cuerpo humano que evoca cierta disposición de alma que le sirve de origen". Tal definición, que pretende abarcar a la vez la postura corporal y el estado psicológico considerados como dos realidades distintas, es una clara consecuencia del viejo mito cartesiano del "fantasma en la máquina", que Ryle ha denunciado tan enérgicamente.

No obstante la fuerza de la tradición y a pesar de graves divergencias, los investigadores se han visto llevados a utilizar el concepto de actitud para tratar con resultados de observaciones y experiencias registrados en forma objetiva. La psicología y las ciencias sociales recogieron el término del lenguaje ordinario conservando todas sus notas, especialmente el uso disposicional y el significado de adaptabilidad o ajuste a varias situaciones. Los psicólogos experimentales, principalmente en Alemania, fueron los primeros en introducir el concepto de actitud en el lenguaje científico y, en los últimos. años del siglo pasado ya era corriente en todas las investigaciones psicológicas. William James llamó la atención sobre algunos aspectos de las actitudes, decisivos para cuestiones de significado y de comportamiento; Koffka estableció distinciones entre actitudes; Washburn insistió sobre su carácter sistemático; pero sobre todo, Freud hizo posible que el concepto pasara a manos de los sociólogos, mejor dicho, pasara a ser un concepto interdisciplinario. Punto de encuentro entre reacciones personales y reacciones de grupo; más impersonal que las visiones naturalistas del instinto y, por otra parte, menos impersonal que las costumbres o las fuerzas sociales, el término de actitud vino a convertirse en la noción clave de la psicología social, indis- 
pensable para establecer un puente entre el estudio de la personalidad y el de la cultura como sistema de valores y de creencias.

El desarrollo de la psicología social como disciplina científica se llevó a cabo en el periodo comprendido entre las dos guerras mundiales, y el asunto de las actitudes fue el apoyo principal de sus investigaciones empíricas. Se trabajó en construcción de escalas para medir la dirección de las actitudes, a partir de L. L. Thurston principalmente; por los mismos años se inició la investigación de actitudes de grupos sociales particulares en relación a objetos de interés común, sobre todo a partir de los trabajos de Thomas y Znaniecki. Estos dos investigadores definían la psicología social como "el estudio científico de las actitudes", y dieron a este concepto una prioridad sistemática en sus publicaciones. Después de $194^{\circ}$ se amplió el campo de estos estudios, se hizo más sistemático $\mathrm{y}$, sin abandonar los temas señalados, se orientó la investigación hacia otros asuntos: el contenido de las actitudes; la manera en que las nuevas experiencias pueden modificarlas; la relación de las actitudes con procesos de aprendizaje y recuerdo, percepción y razonamiento; el estudio de los métodos para medir la dirección, el grado y la intensidad de las actitudes; y por último, su relación con otras variables importantes como, por ejemplo, los niveles de inteligencia, la personalidad, el prejuicio.

Gordon W. Allport, una de las figuras más relevantes de la psicología social en los Estados Unidos a lo largo de más de tres décadas, definió en 1935 la actitud como un estado mental y fisiológico de disposición, organizado a través de la experiencia, que ejerce una influencia directiva o dinámica sobre las respuestas individuales frente a todos los objetos y situaciones con los cuales está relacionado. Diez años después, todavía afirmaba el propio Allport que actitud era probablemente el concepto más distintivo e indispensable en la psicología social americana contemporánea. El tratado de Otto Klineberg y el de Solomon E. Asch, confirman el aserto.

Más recientemente, un grupo de psicólogos, principalmente franceses -Paillard, Fraisse, Duijker, Oleron y Meilli-, se reunieron a discutir el tema de la actitud, convocados por la Asociación Francesa de Psicología Científica. En un intento de precisar el concepto vienen a confirmar los elementos característicos arriba señalados y permiten añadir algunos matices sobre los cuales vale la pena llamar la atención.

En primer lugar, los psicólogos establecen importantes distinciones. Por ejemplo, entre la simple reacción y la actitud que se define por su carácter permanente que, de alguna manera, se percibe como un "atributo de la persona". O entre la repetición de reacciones que constituye el hábito y la actitud que no solamente no implica repetición sino que exige que las reacciones adquieran formas diferentes de acuerdo con las situaciones, aunque ligadas entre sí por rasgos de semejanza más o menos precisos, que obligan 
a hablar de esquemas de reacciones, y aun permitirian hablar de sistemas de reacciones, si esta palabra no fuera en este caso demasiado fuerte. Distinguen también los investigadores entre la actitud y el carácter, no obstante ser fenómenos realmente cercanos; hacen ver que el carácter designa un modo de reacción más o menos general que no especifica las situaciones ni los objetos a que se aplica; la actitud, en cambio, a pesar de su generalidad, establece de alguna manera distinciones de valor y jerarquiza objetos. Éste es un punto muy importante que nos permite suponer, en principio, cambios de actitud que no implican cambios de carácter, así como iguales actitudes en sujetos de distinto carácter y viceversa, sin dejar de reconocer que se trata de fenómenos estrechamente conectados. Seguramente otros psicólogos no compartirán esta opinión. Erich Fromm por ejemplo, para quien el núcleo del carácter está en los modos específicos de relacionarse la persona con el mundo exterior, no establece separación alguna entre actitud y carácter y define lo que él llama la "orientación del carácter" como una actitud fundamental, un modo de relacionarse en todos los campos de la experiencia que incluye las respuestas sensoriales, emocionales y mentales.

En segundo lugar, los científicos acentúan el sentido práctico y precursor de la actitud —es decir, la actitud entendida como disposición a actuar con cierta orientación-, a partir de observaciones de la fisiología sobre las posturas corporales y del estudio de los factores de la vida psíquica que, tomados en conjunto, son considerados como la manifestación fundamental y originaria de las actitudes. Wallon, sobre todo, ha llegado a sostener -fundado en el estudio de las formas elementales de actividad tónica en el niño-, que las actitudes posturales constituyen el tronco común de las emociones y de lo que serán más tarde las actitudes mentales. Así viene a ser la actitud una noción clave para explicar, a partir del plano neurofisiológico, el origen de un gran número de operaciones selectivas y anticipadoras que funcionan en el dominio motor, pero también en otros dominios: en la percepción, la afectividad y la inteligencia.

Al precisar las características de la actitud, Oleron ha señalado, además del aspecto dinámico ya indicado, el de selectividad. Cuando alguien adopta una actitud actúa "como si eligiera" entre diversos estímulos o fases de un estímulo e hiciera caso omiso de los otros: elige entre varias interpretaciones posibles, entre varios términos utilizables o simplemente lleva a cabo una conducta haciendo a un lado otras conductas posibles. Con esto mismo queda permitido, por encima de su carácter permanente, el cambio de la actitud: una actitud puede ser abandonada en la medida en que es una selección y toda selección deja perspectivas abiertas. Por otra parte, viene a reforzar la idea de que la actitud lejos de consistir en un conjunto de reacciones adecuadas a los estímulos particulares, es el desarrollo de un sistema de expectativas que escapan al apremio de la situación, y a partir del cual 
surgirán las respuestas en relación con ciertos objetos o especies de objetos de aquella situación.

Esto último está en relación con lo que se ha llamado -en verdad sin acierto- la característica de especificidad de la actitud, que de ninguna manera debe ser interpretada en oposición al aspecto de generalidad de que hemos hablado más arriba en el sentido de abarcar la totalidad de la experiencia humana en cualquier circunstancia. La especificidad debe entenderse como el recurso utilizado precisamente para enfrentarse a aquella totalidad ante las urgencias impuestas por las condiciones de la acción humana: este recurso es la categorización. Uno de los efectos inmediatos en el funcionamiento de las actitudes es el intento de organizar los estímulos de la circunstancia con arreglo a ciertos criterios; bastará solamente con identificar algunos rasgos para ubicar al estímulo dentro de una categoría y, de esta manera, la respuesta dependerá de la forma en que esa categoría se vincule con la actitud. Probablemente más de una distinción tradicional en el campo de la naturaleza podría servir de ejemplo de estos efectos de una actitud, pero resulta mucho más obvio el empleo de la categorización en las relaciones sociales: tomamos actitudes frente a categorías de personas, frente a demócratas o comunistas, intelectuales o delincuentes, anarquistas o judíos. En estos casos, como en muchos otros, introducimos un principio de economía que clasifica personas y suprime diferencias, con lo que se logra una disposición general, más o menos permanente, capaz de orientar nuestras acciones en una dirección privilegiada.

Este principio de economia, lo mismo si se designa como especificidad o como categorización, es un principio de índole afectiva y activa. Las observaciones de los psicólogos han venido a confirmar esta apreciación tradicional de que las actitudes dependen de los estados afectivos. El psicoanálisis insistió firmemente sobre esto, y los filósofos existencialistas lo pusieron nuevamente en circulación. Los dos conceptos fundamentales de Heidegger, el encontrarse (Befindlichkeit) como temple o estado de ánimo y el comprender (Verstehen) son de indole afectiva y activa, y de ninguna manera tienen sentido cognoscitivo. La distinción posterior de Bollnow entre estado de ánimo (Stimmung) y actitud (Haltung) se mantiene en la misma dirección aunque dentro del plano de la psicologia y, más claramente ligada a la tradición, acentúa el carácter "dado" y natural del estado de ánimo frente al "adquirido" y moral de la actitud, pero advirtiendo que ya en el primero se revela el sentido y el valor de la vida, a partir del cual es posible montar el esfuerzo y la disciplina de la conducta moral que surgen en el segundo.

Aunque la mayor parte de los investigadores parece estar de acuerdo en calificar la orientación selectiva y motriz de la actitud como estrictamente emotiva, queriendo decir con esto que la relación emotiva con el objeto es 
lo que crea el compromiso de la acción y determina su naturaleza, no resulta tan fácil esclarecer el punto en todo su detalle. Sin embargo, los psicólogos del Institute of Child Welfare de la Universidad de Minnesota, han llevado a cabo experiencias interesantes. Han tratado de explorar sistemáticamente. cómo aparecen y en qué medida son estables las actitudes infantiles frente a la experiencia externa, y a partir del análisis de las reacciones de los niños en función de sus connotaciones agradables o desagradables - mediante el recuento de sus expresiones de tono afectivo-, han venido a establecer las variaciones de ánimo, la disposición y el tono emotivo con el que encaran la realidad, hasta concluir que una actitud general es el resultado de la suma de aquellas variaciones que han llegado a estabilizarse. De esta manera, habría que aceptar que la actitud no es otra cosa que una disposición surgida de una emoción o un estado afectivo más o menos estabilizado; dicho más precisamente, es el concepto disposicional que podemos utilizar para hacer predicciones a partir de nuestra observación de cierta relación meramente emotiva entre el sujeto y el objeto de la actitud.

Antes de proseguir es necesario hacer dos aclaraciones. La primera en relación con las fuentes de la actitud, la segunda en relación con sus efectos. Lo que interesa destacar en primer lugar es lo siguiente: hemos visto que cuando los psicólogos se preguntan cómo surge una actitud en el niño, responden buscando qué es lo que provoca la repetición y las variaciones de los estados de ánimo para poder establecer la permanencia de una actitud frente a diversos estímulos. De modo semejante, cuando en la vida diaria nos preguntamos cómo llegó Juan a tomar cierta actitud, lo que pedimos es una explicación de orden biográfico y, en rigor, quedamos satisfechos si se nos responde con información sobre su familia, su educación y el círculo de sus amistades, su nacionalidad y clase social, su profesión, etc. En verdad sería más correcto no preguntar cómo sino por qué adoptó Juan esa actitud, y aceptaríamos que se nos respondiera diciendo, por ejemplo, porque fue persuadido o inducido por alguien, o porque careciendo de determinada información y en posesión de ciertas ventajas tuvo que enfrentarse a tal situación, etc. No se pregunta por los caminos o los métodos seguidos, ya que propiamente no puede hablarse de tales, sino por los orígenes o las fuentes de la actitud. Sin excluir la posibilidad de que una actitud pueda surgir de golpe, como resultado de una experiencia traumática o de la estructuración repentina de una situación, lo que se busca al determinar sus fuentes es explicar la relación del sujeto con una determinada situación objetiva y la historia de esta relación en el más amplio sentido de la experiencia: la memoria del pasado y las expectativas del futuro.

La segunda aclaración se refiere a los efectos de la actitud. Cuando decimos que la actitud se origina en una relación de orden emotivo, obviamente no hemos dicho nada todavía sobre sus efectos en el terreno de la 
acción, ni en el dominio cognoscitivo, ni en el propio campo de las reacciones emotivas.

En este punto no sobra recordar lo dicho más arriba sobre la actitud como noción indispensable para entender un gran número de operaciones selectivas y anticipadoras de la acción, de la percepción, de la inteligencia, de la afectividad. El mero adoptar una actitud es ya una actividad de consecuencias externas, y además una actividad orientada en cierta dirección. Los psicólogos hablan de una orientación de la actividad perceptiva y saben que, en igualdad de condiciones, hay estímulos que se presentan como preferentes para ser percibidos por el sujeto, por ejemplo aquellos que le son más familiares, o que le ofrecen mayor atractivo por estar más vinculados a sus intereses, o que en alguna percepción anterior condujeron a una reacción agradable o benéfica. Esto sin hablar de distorsiones perceptivas, de adaptaciones defectuosas, de falta de flexibilidad y hasta de transferencia en el sentido psicoanalítico. Lo mismo han señalado los psicólogos en el plano del razonamiento, que en cualquier individuo está sometido a toda clase de deformaciones; pero aun sin llegar a ellas, es obvio que en procesos como la abstracción las actitudes representan un papel principal, y que en otras operaciones intelectuales se ha podido probar que algunas diferencias individuales de eficiencia no se explican por los hábitos de reacción aprendidos sino simplemente por actitudes. Por último, algo parecido puede decirse de las reacciones emotivas: una actitud previa favorable - aunque ella misma se origine fundamentalmente en estados emotivos- acaba por determinar el carácter agradable de nuevas experiencias a fuerza de oscurecer ciertos rasgos del objeto; y cuando esto mismo se aplica al plano de las relaciones interpersonales, las consecuencias resultan mucho más claras porque a menudo la categorización determina el trato con las personas atendiendo simplemente a uno solo de sus rasgos. El reconocimiento de está interacción por parte de los psicólogos cuando se proponen el problema terapéutico de adaptación de un sujeto, es lo que les ha llevado a un doble tratamiento: en primer lugar a buscar la modificación de los ambientes externos como medio para reducir las tensiones y así favorecer el cambio de actitud; en segundo lugar, al intento de operar directamente sobre el sujeto mismo con el ánimo de reorientarlo y lograr el cambio de actitud.

4. Después de estas aclaraciones sobre las fuentes y los efectos de la actitud, podemos volver al asunto pendiente. Hemos dicho que la mayor parte de los investigadores parecen admitir que las actitudes dependen de factores emotivos. Fraisse, por ejemplo, dice sostener una tesis monista sobre la actitud que consiste en no disociar, en la reacción del sujeto, los aspectos emotivos y cognoscitivos. En realidad, lo que le interesa es no separar la actitud considerada como una fase - una primera fase- de la percepción, que de este modo resulta ser una reacción condicionada. 
Los filósofos existencialistas han interpretado, dentro de su peculiar estilo ontológico, este elemento evaluativo de la emoción, y casi siempre han insistido en su carácter no-cognoscitivo. Es conocido el punto de vista de Sartre que sostiene que la emoción es una manera no racional de aprehender el mundo -s una estructura de la conciencia que es en primer lugar irreflexiva y por tanto no puede ser conciencia de sí misma. Pero es indudable que Sartre ha visto con claridad que cuando el sujeto busca la solución de una dificultad práctica planteada con urgencia, reacciona emotivamente a los estímulos $y$, como no puede demorar su acción, por ejemplo investigando los procesos causales que mueven las cosas del mundo, entonces ensaya cambiarlo, es decir, ensaya vivir como si las relaciones de las cosas y sus potencialidades no estuvieran reguladas por aquellos procesos sino por magia. Cerrado el camino de los cálculos exactos y de los instrumentos, y acorralado por la necesidad de actuar, dice Sartre, el sujeto se lanza en esta nueva actitud con toda la fuerza de que dispone e introduce en el mundo modificaciones que lo hacen aparecer como una totalidad que sólo puede ser manipulada en grandes masas.

Emparentando en esto con la psicología de la forma, que ve en los estados emocionales actos subrogatorios con que el sujeto se protege cuando no halla soluciones, Sartre habla de estos ensayos emotivos de modificar el mundo como de una conciencia degradada, y del mundo mágico que surge de ellos dice que es un mundo coherente pero irracional. La emoción, para Sartre, lejos de ser un desorden pasajero del espíritu, es el retorno a la actitud mágica. El reconocimiento del elemento evaluativo pero irracional de la emoción es un paso para degradarla. Sin embargo, los supuestos sobre los cuales trabaja Sartre y la intención de su Esquema de una teoría de las emociones, no le obligan a distinguir con precisión el concepto de actitud que él mismo usa, aunque deje bien claro que la emoción es seguramente su condición necesaria y básica.

La razón de estas dificultades se encuentra en la complejidad misma de la palabra emotividad. En esta palabra se incluyen estados de ánimo, inclinaciones o motivaciones, conmociones y sentimientos, es decir, se incluyen propensiones y acontecimientos psicológicos de diverso tipo, que ahora no podemos detenernos a analizar, y de los cuales no es posible decir muchas cosas en común. Las teorías tradicionales de la emoción señalan con mayor - menor energía una serie de factores: una turbación de la mente o del cuerpo; una sensación corporal; una tendencia a actuar; un sentimiento de cierta clase; una evaluación o conocimiento de algo que de alguna manera lo registra como deseable o no. Pero la mayor parte de esas teorfas discute todavía cuál de estos factores es central, cuál es sólo un efecto, cuál un elemento concomitante, y no acaba de aceptar la posibilidad de que todos ellos integren un fenómeno complejo. 
Recientemente, Alston ha propuesto una visión más comprensiva de la emoción como un complejo de cogniciones, sensaciones y tendencias que, sin embargo, reconoce la posibilidad de casos marginales en que alguno de los elementos se encuentre ausente. A pesar de esta salvedad, la definición de Alston tiene la ventaja de dar un lugar a los constituyentes cognoscitivos de la cmoción y de eliminar la idea, todavía generalizada en ciertos círculos, de que los estados emocionales son meras turbulencias psicológicas inanalizables y absolutamente no cognoscitivas. Todo lo cual contribuye a hacer patente la relación cercana entre las emociones y las actitudes pero no impide su distinción clara.

En la emoción se dan efectivamente, además de las turbaciones y sensaciones corporales, tendencias a actuar, sentimientos y evaluaciones o conocimientos de algo como deseable o no. En la medida en que todo esto se da como una simple reacción aislada, o incluso como repetición de hábito, no es todavia suficiente para que pueda hablarse de actitud, aunque sin duda es condición necesaria. Ya en el lenguaje ordinario, según hemos visto, se da un mayor nivel de complejidad en cuanto que usamos la palabra actitud para designar la disposición de alguien a reaccionar, concretamente la disposición para actuar de cierta manera en relación con un objeto o un grupo de objetos; hacer cierta clase de juicios - de preferencia juicios de valor- en general acordes con sus acciones; y experimentar los estados cmocionales que normalmente acompañan estas acciones y aquellos juicios. $\mathrm{Y}$ por encima de todo esto, podemos reconocer cierta semejanza entre este conjunto de disposiciones y otros del mismo sujeto.

También señalamos, aunque valiéndonos de indicaciones muy rápidas, que los investigadores científicos acentúan este valor disposicional del término actitud frente a las simples reacciones o sentimientos aislados que por sí mismos no nos autorizan a esperar nada. Además, los investigadores enlazan a esta disposición algunas características y ciertas observaciones sobre sus fuentes y sus efectos que confirman y dan precisión al uso corriente: A) su sentido práctico, lo mismo por responder a urgencias de la acción que por orientar de cierta manera tales respuestas, atendiendo en esto no sólo a los estímulos objetivos y a las exigencias emotivas sino incluso a más profundas exigencias de orden fisiológico; $B$ ) en segundo lugar su carácter constante o relativamente permanente, que por supuesto no excluye la variación ni aun el cambio brusco; $C$ ) su carácter selectivo, en razón de que al dirigir la actividad puede hacer uso de un conjunto de expectativas que destacan algunos objetos o grupos de objetos, escapando así al apremio de la situación; $D$ ) en relación con lo que se acaba de decir, es preciso acentuar la liga de parentesco que se da entre las diversas expectativas y su capacidad de adaptación sin alterar los rasgos de semejanza, que es lo que hace posible hablar de esquemas o sistemas de reacciones; $E$ ) su generalidad, que es una 
consecuencia de lo anterior, en el sentido de abarcar la totalidad de la experiencia humana, y a un tiempo su capacidad de modificar esa totalidad, de categorizarla, organizando el mundo en grandes sectores; $F$ ) su dependencia indudable de los estados emotivos a través de los cuales la actitud se estabiliza y cuyo estudio permite establecer las fuentes de la actitud; G) pero al mismo tiempo, el reconocimiento de que las actitudes no son pura irracionalidad; en virtud de que existen también ingredientes cognoscitivos en las emociones; $H$ ) finalmente sus efectos probados en gran número de operaciones selectivas y anticipadoras de la acción, de la percepción, de la inteligencia y de la afectividad, que hacen ver hasta qué punto la actitud revierte sobre sus propias fuentes.

5. Todavía cabe añadir algo, porque hemos venido hablando de actitudes como si se tratara de una noción general a la que debiéramos agregar ciertas características para que se precisara como actitud moral. La discusión de Alston en contra de Stevenson y los emotivistas se coloca precisamente en este terreno. Pero aquí vamos a sostener que cuando se trata verdaderamente de actitudes, se trata de actitudes morales que no desligan las cuestiones de la vida práctica del valor y del sentido del mundo. Las especificaciones son más bien derivadas de este campo moral originario a otros campos que pueden estar conectados con él, como la religión, la metafísica o la política.

En pasajes anteriores hemos insistido suficientemente en el carácter práctico de la actitud. Esto mismo ha permitido ver que los simples estados afectivos, gustos y preferencias, aspiraciones y simpatías que nos disponen a favor o en contra de algo, no son actitudes, ni siquiera en el caso de que aquellas disposiciones fueran acompañadas de juicios de valor y de discursos que alaban o condenan el objeto. Es indispensable la disposición a la acción que debe ser adecuada a las preferencias afectivas y a los juicios, pero que no se sigue de ellos. Se puede hablar de actitud sólo cuando se aprueba algo emotivamente, se hacen declaraciones consecuentes sobre su valor $y$, al mismo tiempo, se está dispuesto a un cierto comportamiento para propiciar que lo aprobado se difunda, se repita, se conserve o crezca. Ahora bien, esta disponibilidad para la acción es en términos estrictos un compromiso moral que caracteriza la actitud. Las llamadas actitudes estéticas, en la medida en que no son otra cosa que la aplicación de un cierto procedimiento técnico de creación, el uso de meras tácticas o recetas, ni reúnen los elementos que constituyen la actitud ni tienen que ver con el problema que aquí nos interesa. Cuando se trata de enfrentarse a la creación artística misma como una acción humana requerida de justificación, se ha pasado a otro nivel que puede dar lugar a actitudes específicas, siempre ligadas al campo moral originario.

El compromiso moral permite explicar muchos de los efectos de la acti- 
tud en los estados afectivos. De la disposición a actuar que es parte constitutiva de la actitud se siguen, por ejemplo, la disposición a sentirse obligado a cumplir ciertos actos, a sentirse culpable de no haberlos cumplido, a sentir indignación contra quienes no los cumplen.

Alston ha llamado la atención sobre la conexión indudable que se da entre los tres elementos disposicionales que constituyen la actitud -el estado emocional, la acción y el juicio-, pero no ha visto que era suficiente que tales elementos se conectaran adecuadamente para considerar toda actitud como compromiso de acción y por tanto como moral. Por eso mismo ha tenido que buscar otras bases para distinguir entre varias clases de actitudes atendiendo a los contenidos cognoscitivos de los estados emocionales, a la relevancia moral de las acciones mismas, al alcance normativo de los enunciados y hasta al uso de términos morales. Sin tomar en cuenta que el carácter moral no le viene a todo esto en virtud del uso de ciertos términos o de la forma lógica de los enunciados sino de la función que desempeñan en el lenguaje ordinario para justificar acciones, para exhortar o persuadir a quienes han de ejecutarlas.

Pero aún debemos insistir en otro punto, señalado de modo muy general al tratar del uso ordinario de la noción de actitud y con mayor precisión en el parágrafo que resume observaciones de diversos investigadores. Las notas alli registradas, especialmente las que se refieren a permanencia, selectividad, capacidad de adaptación y generalidad de la actitud, impiden que ésta pueda considerarse como la disposición a un solo conjunto de reacciones -un cierto estado emocional, una determinada acción, un juicio de valor - frente a un solo objeto o conjunto de objetos, por más que las reacciones pudieran ser repetidas o incluso habituales. La noción misma de actitud exige tener en cuenta una pluralidad de esquemas de reacciones capaces de enfrentarse a un conjunto no menos amplio de situaciones sin perder sus rasgos de semejanza, su unidad de estilo, que es lo que hace posible utilizarla como concepto unificador de nuestras relaciones con el mundo y con los otros hombres. Precisamente la comparación de varias reacciones que en alguna medida difieren por la circunstancia y el objeto - nunca la mera repetición- es lo que permite hablar de la coherencia de la actitud y distinguir a ésta del hábito. Entre los tres elementos disposicionales, acción, estado emocional y juicio, decimos que hay adecuación, pero entre varins conjuntos de esta naturaleza decimos que hay coherencia. La conducta habitual puede ser calificada de vacilante $u$ obstinada, de firme o intermitente, pero no tiene sentido decir que es coherente, porque este último adjetivo requiere la comparación con otros conjuntos de reacciones, no para medir la repetición de éstas, sino la constancia de ciertas relaciones entre las variables que están en juego. Como se mantiene un punto de vista, así se mantiene una actitud: permaneciendo frente a circunstancias y objetos que cam- 
bian, aunque no se trate de cambios sustanciales. Esto es lo que los psicólogos quieren decir cuando se refieren a la actitud como un sistema de hábitos o como un conjunto organizado de esquemas susceptibles de cierta plasticidad. Si bien sabemos que, en rigor, no puede hablarse ni remotamente de sistema.

Antes hemos señalado la relación entre la permanencia y la plasticidad de la actitud con esta generalidad y capacidad para modificar el mundo y organizarlo en categorías. No parece necesario acudir nuevamente a ejemplos complejos como aquel que nos sirvió de punto de partida, porque hasta las más obstinadas y elementales actitudes políticas ilustran tal poder de categorización frente a comunidades humanas enteras. Ahora se trata simplemente de insistir en que estos rasgos caracteristicos vienen a confirmar hasta qué punto queda supeditada la actitud a la acción humana y cumple funciones no sólo de preparación para la acción sino sobre todo de justificación, tratando de ligar al sujeto con los valores de las cosas - de la totalidad de las cosas-, es decir, cumple funciones esencialmente morales.

Sin embargo, esto último no es siempre reconocido, a pesar de que la noción de actitud se encuentra repetida a lo largo de toda la historia del pensamiento moral, a pesar de que ciertos conceptos como "bien y mal" se presentan también desde antiguo como una oposición que se da dentro de cada categoría y es aplicable a toda cosa. Es probable que la pretensión de generalidad, que se deriva normalmente de toda actitud en la medida en que puede operar como mecanismo de justificación, haya contribuido a dejar caer en el olvido su carácter moral. Porque frente a esa pretensión se han destacado al menos dos hechos de tan grande volumen que han terminado por ocultarla totalmente a los ojos del observador superficial.

En primer lugar, nos referimos a un fenómeno de la moralidad misma. La época moderna ha contribuido a la vida moral con una abundante literatura de máximas, que se presentan desprendidas de sus supuestos y sus implicaciones - aunque a veces se den ilustradas con modelos de la mejor literatura-, dejando la falsa impresión de que la actitud moral puede ser considerada como una variedad aislada entre otras actitudes específicas. Semejante suposición implica que el juicio moral puede permanecer en los. primeros niveles, es decir, puede quedar reducido a la mera comprobación: de una afirmación moral particular por su adecuación a ciertas reglas $y$, cuando más, al cotejo de la validez de estas reglas por medio de una norma suprema. Pero esto último desconoce que la justificación de la adopción de una norma suprema tiene que hacerse en términos estrictamente extranormativos, dicho de otro modo, en términos de un esquema más o menos coherente de ideales, de enunciados generales y juicios de valor capaces de enfrentar la totalidad de la experiencia humana y establecer conexiones entre las decisiones del sujeto y el resto del mundo. 
En segundo lugar, nos referimos a un hecho de la investigación científica. Por una parte, los trabajos de la psicología orientados a precisar los efectos de la actitud en la percepción y en las actividades intelectuales, o la forma en que ciertas experiencias afectan el surgimiento y cambio de las actitudes, organizan sus observaciones en torno a ejemplos muy simples que permitan un amplio margen de comparaciones y de repeticiones verificables. Los sociólogos, por su parte, interesados en cuestiones de opinión pública, resultados de propaganda, hostilidad entre grupos o diferencias de creencias, dirigen sus encuestas a establecer la dirección y el grado en que los sentimientos de aprobación o desaprobación se asocian a un objeto bien determinado. Este objeto puede ser una idea o un slogan, una institución o una persona, un símbolo o un ideal, al presentarse aisladamente, contribuyen a que se pierda de vista el concepto general de actitud. Muchas veces, se distingue una variedad de actitudes específicas independientes alli donde sólo hay aplicación de procedimientos o de métodos para resolver cuestiones teóricas o prácticas; repetición más o menos habitual de ciertas conductas; o simplemente efectos reiterados de una actitud moral fundamental, ligada en su origen a representaciones generales sobre la totalidad de la realidad.

Ahora bien, estas representaciones unitarias de las relaciones del hombre y el mundo pueden ser más o menos racionales. La organización del mundo en categorías comienza a constituirse -como dice Allport- en base a un germen de verdad. Sin embargo, a pesar de contener elementos cognoscitivos, no son una descripción estricta de la realidad -cualquiera que sea la relación que mantengan con ésta-, sino sobre todo un conjunto de ideales de vida, de deseos, esperanzas y nostalgias, en parte modificaciones imaginarias de la realidad a partir de las cuales podemos elegir los marcos de referencia de toda consideración moral, la norma suprema que convalida todas las demás reglas de conducta. Más adelante veremos que la elección de tales marcos o normas fundamentales también debe ser justificada o, de acuerdo con la terminologia de Feigl, debe ser vindicada.

Discutido el concepto de actitud, podemos decir, sin temor a que no resulte claro el alcance de la afirmación, que la filosofía entendida como concepción del mundo no es otra cosa que la expresión de una actitud moral. El sabio o el filósofo en este amplio sentido ideológico puede construir un edificio más o menos simple o una doctrina notable por la riqueza en la elaboración de los detalles, pero en todo caso, lo que hace es aprovechar el lenguaje para presentarse a sí mismo como teniendo una actitud.

6. Vengamos ahora a otro punto que fue tocado lateralmente a propósito de las llamadas actitudes estéticas. A menudo se dice de alguien que "adoptá una actitud cientifica", o se pide que cambie la "actitud filosófica hacia un problema", o incluso se habla de "actitud metodológica". Pero en ninguno de estos casos se usa el término en el sentido definido anterior- 
mente de actitud moral, o en el sentido más específico y derivado, pór ejemplo, de actitud política. Se trata de algo del todo distinto que no parece que pueda designarse justamente de otra manera que con la palabra "método": se nos pide que cambiemos de método frente a un problema, que adoptemos un método determinado para alcanzar un conocimiento. Entre método y actitud, a pesar de posibles semejanzas - puesto que en ambos se trata de encarar de cierto modo estímulos propuestos-, se da una diferencia de naturaleza y no simplemente de niveles de complejidad. Los autores de lengua inglesa emplean dos términos que, al menos en parte, parecen corresponder a esta distinción. La palabra attitude se emplea para designar modos de reacción más o menos permanentes y estables que guardan cierto grado de generalidad; mientras que la palabra set se usa para designar una disposición limitada a cierta tarea o a aspectos precisos de cierta tarea.

Merece la pena insistir en esta diferencia entre actitud y método uno de cuyos aspectos quedó apuntado en el apartado 2 de este trabajo. El aspecto fundamental parece ser el siguiente: cuando decimos que alguien adopta un método científico, hablamos de una tarea y de la disposición a una tarea en la que los intereses cognoscitivos tienen una primacía incuestionable: de la misma manera, cuando se trata de aplicaciones prácticas de conocimientos científicos se mantiene el predominio cognoscitivo aunque sea a un nivel meramente instrumental, que suspende la relación afectiva entre sujeto y objeto imponiendo una cierta distancia. Cuando se habla de actitudes, ya no se da esa primacía sino algo distinto que es la primacía evaluativa, la cual encuentra su apoyo en estados emocionales del sujeto.

Para acabar de dibujar los limites de aplicación del concepto de actitud es indispensable mantener la distinción que se acaba de señalar, pero el asunto es de suyo demasiado complicado para que se puedan decir aquí cosas muy esclarecedoras. Lo que se dice a continuación debe valer como un índice de cuestiones, adecuado para justificar la distinción de que se habla y, por supuesto, merecedor de un tratamiento detenido en busca de respuestas fundadas que aquí no puede tener lugar.

Cuando se reconoce la primacía evaluativa de la actitud y su apoyo en los estados emocionales del sujeto, no se quiere decir que no se den en ella, como se dan en las emociones mismas -y consecuentemente en aquellos productos culturales que hemos señalado como su expresión-, elementos cognoscitivos. Ni tampoco se da por supuesto que, en actitudes muy elaboradas, tales elementos no puedan presentarse incluso como descripciones o como premisas de hecho a partir de las cuales se puedan hacer surgir conclusiones valorativas y, con esto, dar ocasión a los argumentos morales. Todo esto es posible como se ha dicho antes, sobre todo cuando el juicio moral permanece en los primeros niveles. Pero con frecuencia, las discusiones acerca de este tipo de problemas no requieren simplemente aducir 
observaciones que están al alcance de todo el mundo o que pueden ser establecidas por algún procedimiento técnico más o menos claro, sino que acuden a otras instancias menos accesibles y más dependientes de los estados emocionales, la imaginación y la propia experiencia vivida, que están en las fuentes mismas de las actitudes. En tales casos, no solamente es difícil lograr acuerdos, superar inevitables ambigüedades y malentendidos, sino incluso es imposible acudir a lo que en términos ordinarios llamamos un argumento moral.

Algo parecido acontece con otro problema que no encierra dificultades menores: el que se refiere a la aplicación de un método para obtener conocimientos científicos. Nadie discute la primacia cognoscitiva y existe un acuerdo general sobre el hecho de que ciertas operaciones intelectuales como describir, teorizar, explicar y predecir, son neutrales desde el punto de vista de la valuación y la normatividad. Sin embargo, habría que añadir un par de consideraciones: en primer lugar, es obligado reconocer que, aunque el punto puede defenderse, el acuerdo deja de ser unánime cuando se trata de las ciencias sociales; además, es frecuente que en los procesos de investigación, el científico se encuentre con la necesidad de aplicar, al menos dentro de ciertos límites, criterios que ya no son neutrales desde el punto de vista valorativo, por ejemplo, cuando tiene que optar entre varias hipótesis que se excluyen y para ello acudir a un cierto marco de referencia conceptual que por su generalidad ya no cae bajo su control inquisitivo.

Ahora bien, aquella diferencia fundamental puede encararse desde diversos ángulos y contribuir a explicar muchas diferencias secundarias. Por ejemplo, decimos que la tarea cientifica nos lleva a conocer, es decir, a disponer de ciertos conocimientos lo que a su vez nos da competencia o capacidad para hacer ciertas cosas; y el camino que nos conduce a esta capacidad se llama con toda precisión método. En cambio, las actitudes, por muy elaboradas y sabias que sean no nos llevan fundamentalmente a conocer sino a creer - de acuerdo con Ryle creer es un verbo de motivación o de tendencia-, y con ello nos disponen a actuar de cierta manera. A esta tendencia o disposición no se llega por un determinado camino válido para todos los sujetos. Según hemos visto, la actitud no tiene métodos sino sobre todo fuentes. $\mathrm{Y}$ así, podemos preguntar a alguien qué es lo que le hace creer tal cosa, o por qué mantiene tal actitud, y aceptamos respuestas que de ninguna manera podrían aplicarse al saber o a los métodos de investigación. "Su actitud impide que lleguemos a un acuerdo" o "no puedo menos que mantener esta actitud", son expresiones que pueden ser dichas en una discusión moral -en rigor, para acabar con la discusión-, porque suponen fuentes y creencias, pero que no pueden aplicarse a la tarea científica ni a la filosofía considerada en su sentido más estricto, que usan 
determinados métodos para alcanzar un saber. En estos casos, el método queda de tal manera ligado al saber que se busca y a sus pretensiones de validez universal que tiene que ser exhibido en todos sus pasos junto con él, para que pueda ser verificado por otros investigadores. La actitud, en cambio, no tiene que mostrar sus fuentes y carece de tales controles.

En la medida en que sus expresiones doctrinarias no pretenden validez general sino que se presentan como ideales personales o de grupo, los hombres sabios pueden hacer un llamado a la confianza, pueden eludir toda discusión sobre las fuentes de la actitud, decir que no están obligados a confesarlas o declarar que son inefables. La discusión sobre la autenticidad de una actitud tiene que ser medida con criterios de indole moral totalmente diferentes que, además, han de tener en cuenta el compromiso de acción que envuelve el aceptar ideas y creencias derivadas de tal actitud.

La imposibilidad de verificación, o como quiera que se llamen las formas de control que se ejercen sobre los enunciados de la ciencia mediante la argumentación lógica y la prueba empírica, contribuye a acentuar en la obra de los moralistas y, por tanto, en toda concepción del mundo, ciertas características que tienen una evidente relación con la actitud y que se oponen a otros tantos rasgos de la ciencia. Solamente para ilustrar esa relación, puesto que el tratamiento detenido del tema rebasaría los límites de este ensayo, diremos que todas aquellas construcciones doctrinales que se han señalado como expresión de actitudes, en especial las llamadas concepciones del mundo, suelen poner al descubierto a) su dependencia de la acción, en el doble sentido de contribuir a orientarla en una cierta dirección y de exhibir justificaciones; b) su carácter constante que, aunque no excluya la variación ni aun el cambio brusco, pretende mantenerse gracias a un formidable poder de adaptación que de modo permanente reinterpreta los nuevos resultados de la investigación científica para ajustarlos a las convicciones o principios de nivel no corroborable que previamente ha aceptado como supuestos; c) su carácter selectivo en cuanto que pueden destacar algunos objetos o grupos privando a otros de todo valor, en provecho de una cierta imagen del mundo y, en último término, de la orientación de la conducta que intentan justificar; d) su generalidad y, a un tiempo, su pretendido carácter sistemático, en la medida en que abarcan la totalidad del mundo organizándolo en grandes sectores o categorías, sobre cada uno de los cuales pueden ofrecer doctrinas que, si no se enlazan como piezas de un sistema, al menos ofrecen entre sí rasgos de semejanza; $e$ ) su indudable relación con las actitudes y, a través de ellas, con los estados emotivos y, en general, con la experiencia vivida de los sujetos; $f$ ) pero al mismo tiempo revelan sus elementos cognoscitivos y, en ocasiones, su necesidad de acudir a descripciones, argumentos y teorfas que pueden ser revisados críticamente, o de hacer suposiciones de modo más o menos explícito y defender creencias que se pueden 
poner en relación con conocimientos científicos corroborables; $g$ ) finalmente su capacidad de influir, en tanto que aparatos doctrinarios, sobre las mismas actitudes de que han surgido, por ejemplo endureciéndolas hasta imposibilitar toda variación a fuerza de presentar justificaciones demasiado rígidas o complejas.

7. Ahora se verá con claridad lo siguiente: una investigación empírica sobre las fuentes de la actitud, aun en el caso de que llegue a establecer estas fuentes en todo su detalle, y se prolongue hasta poner de manifiesto conexiones más o menos invariables entre las actitudes y sus objetos, conduce a una explicación psicológica, histórica o social de sus orígenes, de su permanencia o su rechazo, pero no puede proporcionar una fundamentación.

Una concepción del mundo encuentra su explicación en la exhibición de una actitud, y ésta a su vez puede ser explicada por la investigación de sus fuentes. En rigor, las actitudes -y en consecuencia sus expresiones doctrinales- no pueden fundarse. Menos todavia puede decirse de ellas que sean fundamento de otras actividades teóricas o prácticas. Lo que decimos de una actitud en la experiencia diaria cuando consideramos, por ejemplo, su ajuste con las condiciones de la realidad, su relación con conocimientos empíricos corroborados o el carácter no contradictorio de sus creencias, es que tal actitud se encuentra más o menos justificada. La tarea de toda concepción del mundo y, en general, de toda expresión de actitudes acompañada de juicios de valor, es hacer explícitas estas justificaciones, pero en la mayor parte de los casos hay, además, el intento de presentarlas como verdaderas. En relación a este sector de la cultura, a la filosofía considerada en su sentido estricto le corresponde simplemente la clarificación y el examen de tal intento. A estas precisiones debemos añadir que así como no cabe confundir la justificación de una actitud con la mera explicación de sus fuentes, tampoco se puede aceptar que se mezclen y confundan las razones dadas en apoyo de una actitud con los esfuerzos para difundirla y los recursos meramente persuasivos.

Si las actitudes fueran irracionalidad pura no habría que plantear el problema de su justificación, sino tal vez otras cuestiones relacionadas por ejemplo con las posibilidades y ventajas de su propagación, unificación o diversificación. Pero hemos advertido antes que hay en ellas elementos cognoscitivos a partir de los cuales pueden ser más o menos justificadas; sabemos además que la defensa de estas justificaciones, cuando no su mera exhibición, es una de las funciones que corresponden a las expresiones doctrinales de las actitudes, sobre todo si se presentan como concepciones del mundo; y finalmente, la más elemental experiencia de la vida moral nos enseña que un subjetivismo pleno es inadmisible y que, al menos sobre ciertos aspectos, es posible la discusión, el recurso a la información científica y el argumento. 
La distinción de Feigl, a que se aludió en el apartado 5 de este trabajo, muestra 'perfectamente el campo del argumento moral. Aunque en la experiencia de la vida no se den separados los argumentos que convalidan una afirmación moral particular a una norma moral ordinaria, de aquellos que vindican la norma suprema de un sistema, es fácil distinguirlos mediante el análisis. En el contexto de la validación, que corresponde a los primeros niveles del juicio moral, los principios cognoscitivos son más importantes que las normas mismas: cuando se miden los resultados prácticos de una acción moral se hacen inferencias inductivas; cuando se subsume un caso particular dentro de una regla moral ordinaria se hacen inferencias deductivas; el argumento que justifica una conducta o una norma mostrando su acuerdo con un sistema ético dado, tiene la misma estructura que cualquier análisis de validación en el dominio cognoscitivo. En los asuntos morales, la validación termina con la exhibición de las normas que gobiernan el dominio del argumento, precisamente porque no las pone en cuestión.

El problema se plantea en relación con la vindicación, que ya no es la mera validación de conocimientos sino la justificación del acto de aceptar criterios básicos de valor, ciertos marcos ideales de referencia o normas fundamentales de un sistema moral que, en último término, vienen a expresar nuestra disposición a ciertos actos, juicios y estados emocionales. Esto es lo que debe llamarse con todo rigor la justificación de las actitudes.

Aunque los razonamientos vindicativos deben tener en cuenta conocimientos empíricos, puesto que las actitudes no prescinden por completo de tales elementos, la verdad es que la justificación de las actitudes obliga en primer lugar al planteamiento de cuestiones relativas a la aceptación de principios morales ideales o fines de acción y, en segundo lugar, a cuestiones de conexión entre medios y fines. A partir de aquella aceptación y de esta explicación de conexiones, es posible pasar al dominio de los argumentos, a la validación de los enunciados morales ordinarios o incluso a la justificación de los medios por su adecuación o armonía con los fines o ideales aceptados. Pero sucede que la aceptación misma se encuentra ligada desde sus orígenes a una actitud, surge comprometida con una concepción del mundo que a su vez da expresión a esta actitud y, en tal medida, es inseparable de la serie de condiciones que constituyen sus fuentes. Ahora bien, los riesgos de petición de principio que envuelven este tipo de asuntos, en virtud de las relaciones que antes hemos señalado entre las concepciones del mundo, las actitudes y sus fuentes, hacen imposible la prueba de cualquier principio último de justificación.

En esta grave limitación encuentran sus mejores puntos de apoyo las tradiciones escépticas y relativistas, como encuentran en las descripciones de la antropología y en los relatos de la historia la información necesaria para ilustrar, a propósito de diversos grupos o culturas, diferentes sistemas 
de validación. Sin embargo, es indispensable precisar lo siguiente: efectivamente se dan modos irreductibles de interpretar el mundo -cuerpos de doctrina y actitudes de que dan cuenta la historia de la cultura, la psicología, las ciencias políticas-, y podemos aceptar también que es probable que esta variedad no desaparezca en lo futuro. Pero la historia de la filosofía y la historia de la ciencia dan pruebas indudables de que, si bien las actitudes morales no pueden ser refutadas de manera absoluta, sí lo han sido y sin duda podrán serlo en lo futuro sus expresiones doctrinales, es decir, las concepciones del mundo que a ellas se ligan. Esta diferencia indica el único camino posible para dar razones en favor o en contra de las actitudes y enfrentar unas a otras como más o menos justificadas.

El reconocimiento de estos límites detiene el círculo de la justificación de las actitudes. Al mismo tiempo, la posibilidad de una actividad crítica ejercida - al menos hasta ciertos niveles- sobre las concepciones del mundo, permite reducir a un mínimo las pretensiones del subjetivismo y señala vías de racionalidad.

Aunque una actitud no pueda ser refutada ni justificada de manera completa, la investigación empírica y el análisis filosófico pueden poner en claro muchas cosas en torno a ella. Por ejemplo, pueden contribuir a elucidar: 1) la función de la actitud en el contexto de la acción y la forma en que opera efectivamente frente a las circunstancias sociales, pero además, su función en el contexto del discurso moral y de las concepciones que pretenden justificarla; 2) el fin o el conjunto de fines o ideales morales al servicio de los cuales se pone la actitud con todas sus concepciones, y mostrar, además, su viabilidad o compatibilidad con una determinada estructura social; 3) la compatibilidad o congruencia de los ideales morales entre sí, cuando se dan asociados a una misma actitud, así como la adecuación y la armonía de todos los medios que se ponen a su servicio; 4) la coherencia del sistema de normas y su compatibilidad con los ideales morales que protegen; 5) los supuestos o presuposiciones de las normas, de los ideales por ellas protegidos, y de las concepciones doctrinales asociadas, así como la relación de compatibilidad de estos supuestos con todas las leyes científicas conocidas.

Éstos son justamente los terrenos de las razones en favor y en contra de las actitudes, donde ningún principio último puede ser probado con todo rigor, pero al menos puede escapar a la crítica si muestra la eficacia de su función social, su coherencia lógica y su compatibilidad con los enunciados de la ciencia, y de esta manera presentarse como más justificado que otros principios. Desde diversos ángulos, Findlay y Bunge han insistido en que una genuina justificación tiene que enfrentarse con los supuestos doctrinales, con las creencias que están por debajo de las actitudes, para exhibir su función real en una determinada situación y examinar su debilidad o su 
firmeza desde un punto de vista rigurosamente cientifico. Una actitud puede ser reforzada o parcialmente justificada si se prueba que los supuestos en que se apoya son válidos, que sus creencias son compatibles con los enunciados de la ciencia, o si se muestra la coherencia del sistema de normas y la adecuación de sus ideales con una cierta realidad social. Una actitud exhibe su debilidad en el momento en que no puede cumplir estas exigencias lógicas y empíricas. He aquí un ejemplo simplificado pero posible: en una sociedad esclavista puede parecer congruente la actitud que discrimina a los hombres de color, pero esa actitud y las normas morales que de ella derivan presentan a su favor una serie de creencias sobre el origen y el destino de los negros - como descendientes de Cam, hijo de Noé, condenados por éste a ser eternamente siervos-, y además presuponen una hipótesis de desigualdad racial. La creencia como tal rebasa los niveles de lo que puede ser contrastado con informaciones empiricas, pero eso mismo la deja en el terreno de lo no exigible, desprovista de toda objetividad; la hipótesis, en cambio, puede ser sometida a prueba y su falsedad puede ser demostrada; por otra parte, la investigación de las formas de organización social puede revelar la función ideológica de tales creencias, supuestos y expresiones doctrinales.

8. Lo dicho hasta aquí explica plenamente las funciones morales de las actitudes y de sus expresiones doctrinales, es decir, sus funciones al servicio de la acción. Lo mismo la vida individual que las empresas colectivas exigen ideales orientadores y recursos de diversa índole para abreviar los pasos de la acción, sobre ciertas líneas que ni pueden ser la espontaneidad pura ni pueden ser establecidas por conocimientos rigurosos -no importa ahora si por insuficiencia actual o por incapacidad de naturaleza de la ciencia. Mas el reconocimiento de estas exigencias no impide aceptar la función crítica que corresponde a la filosofía en sentido estricto -naturalmente con el auxilio indispensable de las ciencias- sobre aquellos productos culturales $y$, de manera indirecta, sobre las propias actitudes.

Para orientar su conducta, los hombres se sirven de una imagen del mundo, de un sistema de ideales y de creencias, pero la urgencia de la acción y la dependencia de estas formaciones culturales respecto de las propias actitudes, hacen muy difícil enfrentar tales formaciones de una manera racional y lúcida. La incorregible vocación de los metafísicos en busca de un conocimiento riguroso ilustra claramente esta dificultad. Los marxistas son menos ingenuos y presentan sus doctrinas a la vez como ciencia e ideología, como conocimiento riguroso al mismo tiempo que como expresión de actitudes.

Frente a la impaciencia de los moralistas, no parece quedar a la filosofía otro camino que el de hacer patente el carácter provisional y no fundado de aquellas concepciones que, al venir en auxilio de la acción moral, 
contribuyen a su eficacia práctica. Este doble reconocimiento permite retomar la cuestión planteada en las primeras páginas de este ensayo: una vez mostrado el ángulo de la distinción entre la filosofía como expresión de actitudes y la filosofía como actividad metódica rigurosamente racional, es posible admitir no sólo su compatibilidad práctica sino su relación en el plano teórico. Sin negar otras conexiones posibles y, sobre todo, sin dejar de repetir nuestra advertencia en el sentido de que lo que ahora se apunta es apenas una primera respuesta necesitada de más detallados desarrollos, podemos concluir con un par de breves consideraciones.

Una concepción del mundo puede ser descrita como una hipótesis muy general y de muy largo alcance. Aparentemente nada impide preparar, a partir de ella, predicciones sobre acontecimientos futuros o deducir ciertos enunciados de nivel menos general que puedan ser sometidos a procedimientos de prueba. Pero sería un error suponer que se trata efectivamente de una hipótesis científica, útil para el avance de los conocimientos. Es necesario tener en cuenta que una concepción del mundo no sólo contiene enunciados fácticos sino preponderantemente enunciados de valor y suele mezclar, al lado de creencias de toda índole, tantos motivos subordinados a la actitud y a la acción, que no cabe establecer entre ellos enlace sistemático. Esta mezcla y falta de enlace impiden realmente que el examen de un enunciado afecte a la concepción del mundo en toda su generalidad, le permiten absorber cualquier objeción a elementos particulares aceptando cambios menores y, en rigor, la hacen permanecer más allá de los riesgos de la refutación.

Es verdad que un investigador puede preparar sus conjeturas con cierta libertad y, en principio, obedecer para ello a los más diversos estímulos, que no excluyen las propias concepciones del mundo; pero también es verdad que la hipótesis que anticipa a título provisional debe cumplir algunos requisitos, entre los cuales no es precisamente el menor su capacidad para ser contrastada con la experiencia. Ésta es la razón de que las ciencias empíricas tomen por lo común como punto de partida una clase de enunciados metódicamente seleccionados y contrastables por observación intersubjetiva, para después integrar una teoría más general, que una vez experimentada permitirá ensayar nuevas hipótesis con mayor nivel de universalidad. Las concepciones del mundo, al contrario, tienen como punto de arranque la totalidad de los enunciados que un individuo acepta acerca de la totalidad de la realidad, sin otras bases que su propia experiencia vivida.

La marcha de la investigación cientifica adelanta exactamente en sentido inverso a como proceden las concepciones del mundo, por eso mismo no puede utilizarlas como hipótesis de trabajo. Menos todavía puede decirse que las necesite como fundamento, cuando lo que requiere para su 
tarea es el establecimiento de enunciados corroborados relativos a hechos empíricos bien delimitados y, cuando más, la elucidación de cuestiones lógicas y epistemológicas igualmente precisas que nada tienen que ver con las opiniones de los hombres sabios. Algo semejante puede decirse de la filosofía en sentido estricto, en la medida en que ha renunciado a una visión íntegra de la totalidad del universo y sabe disciplinar sus puntos de vista al desarrollo de un saber objetivo y fragmentario. Sin embargo, en este punto cabe una excepción: cuando en el curso de su trabajo el científico se encuentra con que tiene que aplicar criterios que no son completamente neutrales - por ejemplo al elegir entre varias hipótesis- y para ello acudir a ideas organizadoras muy generales o a marcos de referencia muy cercanos a sus propias concepciones del mundo.

Otro problema totalmente distinto es el de la justificación moral de la filosofía en sentido estricto como tarea humana o ejercicio profesional, que no es sino un caso particular de la justificación de cualquier conducta $y$, por tanto, abre la perspectiva de la relación entre la función moral de las actitudes y de las concepciones del mundo, con la filosofía considerada como una actividad dirigida a obtener conocimientos. Pero esto no es asunto que pueda ser tratado aquí. Lo que nos interesa, y constituye el. último punto por considerar en este ensayo, es la función crítica de la filosofía en sentido estricto frente a las concepciones del mundo e, indirectamente, frente a las actitudes.

La filosofía en sentido estricto, se enfrenta a las concepciones del mundo, como a las ciencias, a las artes y a cualquiera de los sectores de la vida cultural de las sociedades; pero no se confunde con ninguno de ellos. A la filosofía no le corresponde determinar los ideales de la vida y no disputa, ni con los moralistas ni con los políticos, el derecho a darles una formulación adecuada o a propagarlos; ni con los investigadores de la psicología y las ciencias sociales el derecho a explorar sus complejos orígenes. Todavía más, la filosofía se empeña en mantener muy claramente la distinción de las tareas.

La confusión de límites y la mezcla arbitraria de procedimientos nunca ha sido provechosa para ninguna disciplina. Para la filosofía, el distinguir las propias tareas de los empeños de los moralistas y de los metafísicos, ha significado un avance considerable. En la medida en que la filosofía abandona los lenguajes equívocos y se niega a presentarse como creadora y defensora de los ideales de la humanidad, es decir, en la medida en que deja en manos de la sabiduría la función práctica orientadora de actitudes, se hace apta para conducirnos a determinados conocimientos. Por ejemplo a conocimientos sobre la coherencia de los ideales, la compatibilidad de las normas, la validez de los supuestos y de las concepciones doctrinales que se asocian a aquellos ideales; y también puede advertirnos 
sobre la manera de usar la información de las ciencias empíricas en asuntos relacionados a nuestras acciones y a la transformación efectiva del mundo. En cambio, si subsiste la confusión y se mezclan los atributos de los conceptos teóricos con las consignas prácticas, no sólo se hace más difícil el acceso a los conocimientos válidos y la acción se entorpece, sino que las doctrinas metafísicas, morales y políticas acaban por adquirir un tono dogmático.

Separadas las tareas, la filosofía guarda su interés predominantemente cognoscitivo y permanece en posesión de los instrumentos del análisis. Con estas armas cumple, en primer lugar, una función pedagógica. A todo aquel que se ejercita en ella, enseña hábitos de pensamiento crítico, penetración lógica, precaución frente a creencias y principios. La naturaleza de las cuestiones que plantea la justificación de las actitudes no permite que se dicten reglas metódicas para su solución inmediata, pero es indudable que si se atiende a la complejidad del asunto y se disciplina el discurso moral, las reacciones derivadas de una actitud serán más eficaces, más prudentes y más sabias.

La función fundamental y más característica de la filosofía es, sin embargo, menos directa. Se trata de una función crítica que de ninguna manera tiende simplemente a suprimir la variedad de las actitudes o a unificar el universo de los ideales morales y de las concepciones del mundo. La mera idea de un intento de uniformidad bajo un solo patrón resulta tan intolerable como cualquier sistema metafísico con pretensiones de verdad objetiva. La función crítica de la filosofía no pretende empobrecer el escenario de los ideales humanos y de los modelos personales de virtud moral -del que todos somos cautivos en mayor o menor grado- entre otras razones porque su conocimiento de la variedad de las fuentes de la actitud y de la complejidad de la experiencia moral, le impiden dar por supuesto que todas las cuestiones relacionadas con los principios últimos de la moralidad pueden tener una solución cognoscitiva. Cuando tales soluciones no son posibles, la filosofía en sentido estricto, como la ciencia, tiene que decir que el problema no puede ser resuelto, y considerar que su respuesta es completa. Si se trata de asuntos prácticos de la mayor importancia frente a los cuales no se puede permanecer indiferente, los hombres toman decisiones, realizan actos y hacen evaluación de sus consecuencias. Y como todo esto se hace a partir de actitudes, queda garantizada la pluralidad de los ideales y de los intentos de justificación.

Lo que hace la filosofía al cumplir su función crítica es asegurar el permanente cuestionamiento de toda teoría moral o ideología, de toda concepción del mundo. Frente a la urgencia de las soluciones que impone el ritmo de la acción, la filosofía trata de mantener despierta la conciencia de la complejidad y ejercitar hasta el fin los instrumentos del análisis. En 
este empeño puede alcanzar, casi en su totalidad, a los elementos de cualquier concepción del mundo, al menos a todos aquellos que sean objetivamente discurso significativo -aunque el significado sea puramente emocional y sólo exprese estados subjetivos.

Al hacer claro el lenguaje de las teorías morales, exhibir la dependencia de las pautas de valor respecto de las creencias, examinar el fundamento de éstas y. el rigor de los argumentos, la filosofía puede disolver falsas cuestiones, apartar los elementos puramente míticos y hacer que las afirmaciones de contenido empírico caigan dentro de los dominios acotados por las disciplinas científicas para probar sus credenciales de legitimidad. Y todavía dentro de este campo, se une al trabajo de los expertos como filosofía del conocimiento científico y como crítica del uso social de tal conocimiento y de su justificación.

Semejante tarea, sólo en apariencia modesta, pone en cuestión de manera definitiva el carácter absoluto de las doctrinas últimas de justificación moral y, en general, de las concepciones del mundo. $Y$ además, rompe lazos artificiales que en algunos momentos de su historia -la Ilustración, por ejemplo-, unieron a la filosofía con la retórica para la defensa y la propagación de los ideales de la humanidad. Al hacerlo, la actividad filosófica recobra su tradición más vigorosa y firme: la tradición de la argumentación crítica.

Sería un error suponer, sin embargo, que tales esfuerzos teóricos y muy especialmente críticos, carecen de consecuencia en la vida práctica. Sin insistir sobre los aspectos educativos más arriba apuntados, a propósito de la elucidación, corrección y disciplina de las doctrinas morales y de sus argumentos, conviene llamar la atención sobre un aspecto más directo. Hay que empezar por reconocer que la más laboriosa refutación de un error moral o metafísico no hace otra cosa que mostrar su verdadera estructura lógica, su significación teórica dentro de una doctrina o su función ideológica en una sociedad determinada; pero no le impide permanecer disponible como ideal de vida y ser manipulado como orientador de actitudes más o menos irracionales. Mas también es verdad que exhibir un prejuicio como lo que es, señalar una conducta como movida por un interés egoísta o mostrar las posibles consecuencias de una decisión irracional o coaccionada, tiene que contribuir a multiplicar las oportunidades de decisiones libres, racionales, desinteresadas. La elucidación de las situaciones morales - por vía de la descalificación teórica de concepciones erróneas y del poner al alcance los datos empíricos y conceptuales que hacen posible menores márgenes de error-, considerada como tarea permanente, es una garantía de renovación y de progreso moral.

Precisamente porque la filosofía hace posible un número mayor de decisiones guiadas por el conocimiento, contribuye como ninguna otra acti- 
vidad al progreso moral. Al educar a los hombres en la voluntad de conocer y en la disciplina de la argumentación crítica, deja en sus manos un instrumento necesario para cualquier intento serio de cambiar el mundo y un arma de inflexible rigor en la investigación de la verdad, que puede ser utilizada también como una forma de violencia.

Fernando Salmerón

Instituto de Investigaciones FiLosóficas

Universidad Nacional Autónoma de México 